\title{
DIREITO AO ESQUECIMENTO DIGITAL E RESPONSABILIDADE CIVIL DOS PROVEDORES DE BUSCA NA INTERNET: INTERFACE ENTRE MARCO CIVIL, EXPERIÊNCIA NACIONAL E ESTRANGEIRA E PROJETOS DE LEI N 7881/2014 E N $N^{\circ} 1676 / 2015$
}

\begin{abstract}
RIGHT TO BE DIGITAL FORGOTTEN AND CIVIL LIABILITY OF INTERNET SEARCH PROVIDERS: INTERFACE BETWEEN THE CIVIL MARK, NATIONAL AND FOREIGN EXPERIENCE AND THE LAW PROJECTS No 7881/2014 AND No $1676 / 2015$
\end{abstract}

\author{
${ }^{1}$ Joyceane Bezerra de Menezes \\ ${ }^{2}$ Hian Silva Colaço
}

\section{RESUMO}

A Sociedade da Informação Digital elevou a informação ao patamar de um dos bens jurídicos mais valiosos. Dessa forma, exercer controle sobre as informações pessoais significa ter domínio sobre o espaço pelo qual irá desenvolver-se as potencialidades humanas. Assim, o direito à privacidade, extremamente suscetível no ambiente virtual, caminha no sentido de garantir o direito à autodeterminação informativa, ou melhor, direito ao esquecimento digital. Tal direito decorre diretamente da cláusula geral de proteção da dignidade da pessoa humana. Diante da colisão de princípios fundamentais (direito à privacidade e direito à informação), é possível se extrair os limites para o exercício do direito ao esquecimento no âmbito virtual. A responsabilização civil dos provedores de busca na Internet apresenta-se como principal meio de efetivação do direito em debate; no entanto, a jurisprudência brasileira ainda vem resistindo em reconhecer a responsabilidade do motor de busca em retirar padrões de pesquisa lesivos aos direitos de personalidade. Percebe-se que o marco civil da internet estabeleceu mecanismos de proteção de dados, mas permaneceu silente quanto à responsabilidade dos provedores de busca. Nesse sentido, destacam-se as discussões envolvendo os Projetos de Lei $n^{\circ} 7887 / 2014$ e $n^{\circ} 1676 / 2015$, os quais visam concretizar o direito ao esquecimento digital, na esteira da experiência internacional. Quanto à metodologia, a pesquisa possui cunho bibliográfico e jurisprudencial, pura em relação aos resultados, com estudo descritivoanalítico, desenvolvido por meio de pesquisa teórica quanto ao tipo, de natureza qualitativa e, no tocante aos objetivos, descritiva e exploratória. A título de resultados, concluiu-se que o direito ao esquecimento é um direito fundamental e de personalidade, merecedor de tutela; contudo, deve ser exercido de modo a não suplantar outros direitos de igual porte, concretizando o fim último de proteção e promoção do livre desenvolvimento da pessoa humana. Ao passo que os provedores de busca na Internet podem ser compelidos a remover os padrões de pesquisa com conteúdo ofensivo, pois, ao influenciarem no resultado das buscas, assumem a responsabilidade pela remoção do conteúdo.

Palavras-chave: Direito ao esquecimento digital, Responsabilidade civil, Provedores de busca.

\footnotetext{
${ }^{1}$ Doutora em Direito pela Universidade Federal de Pernambuco - UFPE, Recife, (Brasil). Professora Titular da Universidade de Fortaleza - Unifor, Ceará. E-mail: joyceane@unifor.br

${ }^{2}$ Mestrando em Direito Constitucional pela Universidade de Fortaleza - UNIFOR, Ceará (Brasil). Pesquisador na Área de Direito Civil-Constitucional, Direitos de Personalidade, Responsabilidade Civil e Direito Digital. E-mail: hiancolaco@hotmail.com
} 


\begin{abstract}
The Digital Information Society raised the level of information for one of the most valuable legal rights. This way, exercises control over personal information means to have dominion over the space through which will develop human potential. The right to privacy, extremely susceptible in the virtual environment, walks in ensuring the right to informational self- determination, or better, the right to be digital forgotten. This right stems directly from the general principle of protection of human dignity. In the face of collision of fundamental principles (right to privacy and right to information), it is possible to extract the limits to the exercise of the right to be forgotten in the virtual context. The civil liability of search providers on the Internet presents itself as the primary means of ensuring the right debated, but the Brazilian jurisprudence is still resisting to recognize the search engine's responsibility to remove harmful search patterns to personality rights. It is noticed that the civil framework of the established internet data protection mechanisms, but remained silent about the responsibility of search providers. In this sense, there are the discussions involving the Bills No. 7887/2014 and No. 1676/2015, which are intended to clarify the right to be digital forgotten in the wake of international experience. About the methodology, the research has bibliographic and jurisprudential nature, pure from the results, with descriptive-analytic study, developed through theoretical research on the type of qualitative and, with respect to the objectives, descriptive and exploratory. As a result, it was concluded that the right to be forgotten is a fundamental right and worthy of protection personality, but must be exercised so as not to supplant other deadweight rights, realizing the ultimate goal of protecting and promoting free development the human person. While the search providers on the Internet may be compelled to remove search patterns with offensive content, therefore the influence on the result of the searches, take responsibility for the removal of the content.
\end{abstract}

Keywords: Right to be digital forgotten, Civil liability, Search providers. 


\section{INTRODUÇÃO}

O advento da "Sociedade da Informação" (CASTELLS, 2005) acelerou a dinâmica das relações sociais e, consequentemente, redimensionou a natureza das relações jurídicas, as quais ganharam notória volatilidade em razão do meio virtual. $\mathrm{O}$ ambiente foi transformado de modo tão radical que as pessoas tiveram de se adaptar às mudanças, reestruturando muitos modelos relacionais (WIENER, 1973). Edificou-se uma sociedade de modo panoptizado com o esgarçamento dos limites entre os interesses privados e a "arena pública", na qual se suprimiu o conceito de espaço para uma dimensão liquefeita em superação da ideia de ambiente físico (BAUMAN, 2013).

Em virtude da insaciável sede de informação e da possibilidade de seu armazenamento perene, a tecnologia digital constitui um instrumento de elevada valia para esse modelo de organização social - a sociedade de vigilância (RODOTÀ, 2008), na qual a possibilidade de controle do fluxo das informações pessoais passa a ser um direito de extremada importância... Para tanto, o direito à privacidade sofre uma sensível ampliação a fim de alcançar o desiderado de proteger a circulação e a aplicação dos dados pessoais disponibilizados no meio virtual, suscitando, inclusive, o chamado direito ao esquecimento digital.

No processo de consolidação desse novo direito há, não obstante, certa resistência por parte da jurisprudência nacional, especificamente no que tange à responsabilização dos provedores de busca pela indisponibilização de padrões de pesquisa lesivos ou potencialmente lesivos aos direitos de personalidade. Cumpre ao presente texto, apresentar os argumentos favoráveis ao exercício do direito ao esquecimento digital, por meio da harmonização de princípios constitucionais colidentes, bem como delinear os seus elementos constitutivos, averiguando a sua possível independência e autonomia em face dos demais direitos de personalidade.

A premissa base é a de que o direito ao esquecimento digital tem raízes no direito à privacidade, cuja origem remonta ao "direito de ser deixado só"(WARREN; BRANDEIS, 1890, p. 193) mas que, pelas experiências complexas da sociedade pósindustrial, passa a tutelar a vida privada do sujeito, inclusive, para lhe garantir o controle das informações pessoais que circulam a seu respeito. A partir dessa premissa, o objetivo 
deste estudo é identificar os principais contornos do direito ao esquecimento, sem prejuízo ao direito à informação e sem que a sua garantia possa importar na prática de censura; analisar a possibilidade jurídica de responsabilização civil dos provedores de busca na internet, ambiente no qual se manejarão os instrumentais aptos a efetivação do direito ao esquecimento e ainda analisar a disciplina proposta pela Lei n ${ }^{\circ}$ 12.965/2014 (Marco Civil da Internet) sobre a matéria.

A metodologia utilizada segue uma abordagem qualitativa, descritiva e exploratória, no que toca aos objetivos; bibliográfica quanto ao tipo; pura, quanto ao manejo dos resultados, colhidos a partir de um estudo descritivo-analítico, desenvolvido por meio de pesquisa teórica.

\section{NUANCES DO DIREITO AO ESQUECIMENTO NO CONTEXTO DA SOCIEDADE DA INFORMAÇÃO DIGITAL}

A morfologia da sociedade da informação digital se apresenta como um conjunto entrelaçado de "redes" que modificam substancialmente a operação e os resultados dos processos produtivos e de experiência, poder e cultura (CASTELLS, 2005, p.573). No plano das redes virtuais, expressão genuína das tecnologia fina, as dificuldades para o controle dos processos comunicativos, facilitam os riscos de violação de direitos, demandando desenvolvimento de mecanismos jurídicos aptos à tutela de diversos interesses passíveis de lesão no âmbito virtual, de modo a mitigar os riscos de danos e a ambiência de incerteza e insegurança (DENNINGER, 1993, p. 368).

No primeiro momento já se afirma que houve a ampliação dos contornos do direito à privacidade que passa a proteger as informações pessoais e a vida privada na sociedade da informação, dando azo ao chamado direito ao esquecimento digital, conforme passa-se a demonstrar.

1.1 Direito à privacidade e a proteção das informações: afirmação do direito ao esquecimento digital

As informações constituem, no âmbito da sociedade atual, um dos bens jurídicos mais valiosos. A capacidade de controlá-las, traduz, concretamente, a aquisição de um "poder sobre si mesmo" (MORAES, 2010, p. 58), inferindo-se daqui a sua correlação com o direito à privacidade - direito humano, fundamental e de personalidade. Justifica-se essa 
proteção especial, exatamente em razão da situação de vulnerabilidade da pessoa no meio virtual, dada às inúmeras informações de caráter pessoal circulam sobre ela, muitas vezes sem qualquer controle, na rede mundial de computadores.

A arquitetura da rede virtual favorece a prática de violações a direitos de personalidade, pois o nome e a imagem das pessoas são "vaporizados", afinal, "a internet não esquece" (SCHEREIBER, 2011, p. 164). No atual contexto, "esquecer tornou-se mais caro e difícil, enquanto lembrar é barato e fácil" (MAYER-SCHÖNBERGER, 2009, p. 59). Indagase acerca do perigo de nossas informações ou dados pessoais ficarem armazenados "na rede como se fossem uma tatuagem, que nos seguirá pela vida toda" (CASTELLANO, 2012, p.4).

Por conseguinte, o debate envolvendo a possibilidade de indisponibilizar a veiculação de informações inseridas na rede levou a formulação do chamado "direito ao esquecimento" no âmbito digital. "Esquecer" deixou de ser apenas uma preocupação individual, mas coletiva, pois, gradativamente, as pessoas começaram a refletir sobre os riscos da propagação descontrolada das informações pessoais, fato este que, em breve, poderá culminar com uma diáspora das redes sociais e congêneres (LIMA, 2013, p. 271283).

Como referido, a origem remota do direito ao esquecimento, emergente do direito à privacidade, está na formulação do "The right to privacy" de Brandeis e Warren, assim identificado com o "direito de ser deixado só" (WARREN; BRANDEIS, 1890, p. 193). Na proposta atual, a privacidade se expande para garantir o controle das informações pessoais em circulação na rede, a fim de garantir-lhe o livre desenvolvimento de sua personalidade.

Nesse tocante, em fevereiro de 2007, Viktor Mayer-Schönberger formulou as bases do que chamou "the right to be forgotten", afirmando "esquecer é preciso, pois faz parte da natureza humana, e é uma ação ainda mais necessária na contemporaneidade, onde vivemos sobrecarregados de informações"' (MAYER-SCHÖNBERGER, 2009, p. 7). É contumaz, nesse sentido, que o direito à privacidade ganhou contornos tanto de "reivindicação de indivíduos, grupos ou instituições em determinar por si mesmos, quando, como e quanto de informações sobre si mesmos será comunicado aos outros" (WESTIN, 1967, p.7). 
Nesse aspecto a privacidade envolve o direito à "autodeterminação informativa", que se traduz na "faculdade de o particular determinar e controlar a utilização dos seus dados pessoais" (CANOTILHO, 2000, p. 500). Defende-se a possibilidade de controle espacial, contextual e temporal dos dados, assegurando, portanto, a proteção das escolhas pessoais, após certo período, momento o qual a pessoa não deseja mais ser relembrada por dados passados.

A afirmação do direito ao esquecimento impõe-se diante do reconhecimento da premissa básica de mutabilidade da pessoa, na qual se permite a construção da sua personalidade e a projeção exterior de suas escolhas existenciais livremente, sem imposições que predeterminem a sua história pessoal (BUCAR, on-line, 2015). Assim, é que a privacidade enquanto domínio das escolhas pessoais e das informações personalíssimas acaba convergindo para o direito à identidade que também se subjaz na ideia do direito ao esquecimento digital. A memória digital pode nos impedir de evoluir e mudar. Afirma-se que a "humanidade seguiu seu curso, o curso do qual fazemos parte hoje, graças à capacidade de lembrar do que é importante e descartar memórias desnecessárias” (JEFFRIES, 2011, p. $58)$.

Feitas essas considerações, importa dizer que o direito ao esquecimento digital pode ser subdividido em três diferentes categorias. Na sua feição menos controvertida, corresponde à capacidade de excluir informações disponibilizadas pela própria pessoa no meio virtual, estendendo-se à possibilidade de indisponibilizar tais informações, após terem sido compartilhadas por terceiros e, finalmente, ao poder de controlar a veiculação de dados pessoais disponibilizados por terceiros (FLEISCHER, on-line, 2015).

\subsection{Direito ao esquecimento e seu reconhecimento no cenário brasileiro diante da perspectiva Civil-Constitucional}

O direito ao esquecimento ganhou expressão na doutrina brasileira a partir dos enunciados nos. 404 e 531 da VI Jornada de Direito Civil, os quais, com base na interpretação dos arts. $5^{\circ}, \mathrm{X}$, da CRFB/88 e art. 11 do CC/02, firmaram o entendimento de que este direito se subjaz na proteção da intimidade, da imagem e da vida privada, bem como no princípio de proteção à dignidade da pessoa humana. 
A ausência de limites na propagação de informações disponibilizadas pelos internautas desde a fase juvenil, pode implicar atrapalhar o livre desenvolvimento da personalidade, impondo-lhe prolongadas consequências negativas, aptas a se estenderem para a sua vida adulta. À exemplo, o compartilhamento de vídeo jocoso, ainda na infância, que pode gerar bullying na adolescência.

Em face disso, o direito ao esquecimento na sociedade da informação se apresenta como a possibilidade que tem a pessoa de "conhecer, controlar e interromper o fluxo de informações pessoais, possuindo prévia ciência acerca do espaço informacional sobre o qual desenvolverá sua personalidade, de modo a assegurar a livre construção da esfera privada" (RODOTÀ, 2008, p. 94). Ante a sua congeneridade com o direito à privacidade, é alcançado pela cláusula geral de tutela da pessoa, constituindo a um só tempo direito fundamental e direito de personalidade, cujo substrato valorativo é a dignidade da pessoa humana.

Todos os segmentos da sociedade estão vinculados ao dever de respeito à dignidade da pessoa humana, "epicentro axiológico da ordem constitucional", que irradia efeitos sobre todo o ordenamento jurídico, balizando os atos estatais e as relações privadas que se desenvolvem no seio da sociedade civil e no mercado". (SARMENTO, 2008, p. 86).Disso decorre a importância desse princípio na proteção da pessoa, legitimando um sistema aberto de direitos fundamentais composto por aqueles que se apresentam explícitos no texto constitucional e/ou documentos internacionais e por aqueles que estão implícitos (SARLET, 2009, p. 108). Nessa esteira, é possível sustentar a fundamentalidade material do direito ao esquecimento ou direito à "autodeterminação informativa" (MORAES, 2010, p. 142), foco principal do presente estudo.

Trata-se aqui de um interesse assegurado pelo Direito Civil a partir da pricipiologia constitucional, compreendendo-se que a tutela da personalidade requer proteção integrada, capaz de superar a tradicional dicotomia entre Direito Público e Direito Privado (TEPEDINO, 2008, p. 57). Na perspectiva Civil-Constitucional, os valores solidaristas passaram a nortear os institutos civilistas, atribui-se especial tutela ao aspecto existencial dos direitos da pessoa, assim compreendida numa dimensão coexistencial e não insular (FACHIN, 2006, p. 46). Superada a visão liberal-individualista que tutelava a pessoa 
humana como indivíduo não-socializado e abstraia a importância da vida relacional para o desenvolvimento da personalidade, propõe-se a tutela da pessoa sob a perspectiva inseparável da ideia de solidariedade, valor este que exprime a ideia de cooperação e igualdade na afirmação dos direitos fundamentais (PERLINGIERI, 2008, p. 464).

Sob esses argumentos, sustenta-se a importância do direito ao esquecimento digital para a proteção da dignidade da pessoa humana. É necessário respeitar os processos de desenvolvimento da pessoa, garantindo-lhe alguma privacidade, o respeito à sua honra, imagem e identidade, sob o prisma da solidariedade social e não do individualismo liberal. Não se pode atribuir ao sujeito, um direito absoluto sob todas as informações que lhes são pertinentes, abandonando outros interesses, igualmente legítimos, que venham a sustentar a sua circulação. Porém, é preciso, identificar quais dessas informações são, de fato, importantes para os processos sociais e sopesar, no caso concreto, o interesse que deve ser protegido. A tutela da vida privada e até mesmo do direito de identidade também sofrerá limites no contexto da vida social. Importa verificar quais seriam estes.

\subsection{Parâmetros do direito ao esquecimento: necessária harmonização entre princípios} colidentes

Diante das considerações expostas, os contornos do direito ao esquecimento serão apurados pelo enfrentamento da sua colisão com outros direitos fundamentais, dentre os quais o direito à informação, à liberdade de expressão e à liberdade de imprensa. Será necessário estabelecer os limites razoáveis de proteção aos direitos fundamentais da privacidade e da informação, a fim de harmonizá-los em consonância com o livre desenvolvimento da personalidade (RODOTÀ, 2008, p. 122).

Enquanto o direito ao esquecimento, em geral, procura evitar que a divulgação de fatos ocorridos no passado possam impactar a livre formação da personalidade humana, congelando as potencialidades e a capacidade de progredir da pessoa envolvida;o direito à informação, pautado pelo interesse público na veiculação de fatos históricos em nome do direito à memória e à verdade, também constitui um direito de igual hierarquia. Princípios e direitos fundamentais comportam cargas valorativas que merecem toda a atenção na sua aplicação. Para solucionar os conflitos, há de se considerar também o chamado sopesamento, que consiste na análise da situação de tensão existente entre as partes com 
razoabilidade. (ALEXY, 2008). Nesse desiderato, o enunciado $\mathrm{n}^{\circ} 274$ da VI Jornada de Direito Civil, acerca do art. 11 do Código Civil de 2002, orienta que os direitos de personalidade como expressões da cláusula geral de tutela da pessoa humana, quando colidentes entre si, devem ser interpretados por meio da técnica da ponderação.

No caso do direito ao esquecimento (digital) é mais provável identificar a sua colisão com a liberdade de informação e a proteção da memória individual. A liberdade de expressão, de informação e de imprensa compõe uma tríade dos direitos fundamentais de primeira dimensão muito relevantes do ponto de vista histórico-ideológico, em razão do regime ditatorial vivenciado pelo Brasil, antes da elaboração da Constituição Federal de 1988, que suprimia essas formas de liberdade. Assim, há um grande temor por qualquer manifestação de censura.

Todavia, como não existe qualquer hierarquia ou grau valorativo de relevância entre os direitos fundamentais ou princípios constitucionais, caberá ao intérprete realizar a necessária harmonização, diante do caso concreto, quando houver colisão entre esses princípios.

Aplicada a ponderação necessárias entre os valores em choque, é de se notar que não se pode pretender um direito ao esquecimento digital, cujo exercício venha a suplantar informações de extrema importância do ponto de vista histórico e de notório interesse público, como uma espécie de "censura no retrovisor"(BUCAR, 2015, on-line). Sua aplicação presta-se a garantir que informações inúteis, descontextualizadas e desatualizadas, potencialmente lesivas aos direitos de personalidade, sejam veiculadas sem qualquer controle no meio digital.

Na orientação de Pablo Domingez Martinez (2014, p. 207-208) será necessário considerar os seguintes elementos, antes de aplicar o direito ao esquecimento: "1) domínio público; 2) a preservação do contexto original da informação pretérita; 3) preservação dos direitos da personalidade na rememoração; 4) utilidade na informação e 5) atualidade da informação". Esses critérios servirão ao magistrado como um filtro, no momento em que tiver que aplicar a técnica de ponderação para resolver a colisão desse direito com outros princípios. Ainda que o esquecimento resulte em uma espécie de censura, é imperioso justificar que a sua fundamentação se extrai de um interesse avaliado como superior no caso em exame. 
Injustificável a rememoração de fatos pretéritos, aptos a violar inúmeros direitos de personalidade, se a informação que se pretende relembrar não atingiu, à época, ampla divulgação e publicidade, a integrar a tipificação como domínio público. Considera-se abuso do direito de informar a ampla exposição de fato da vida privada sem notoriedade, prevalecendo, na ponderação, o direito ao esquecimento.

Se a informação ganhou ampla divulgação, ao tempo do fato, outro critério deverá balizar a colisão entre princípios, o da preservação do contexto original da informação pretérita. A veiculação de fatos pretéritos de modo descontextualizado extrapola o legítimo direito de informar. "O contexto da obtenção da imagem e respectiva informação é de extrema importância para o uso justo, sob pena de restar configurada uma falsidade intelectual" (GALVÃO, 2013, p. 34).

Ainda que fato pretérito e de domínio público seja rememorado de modo contextualizado e verídico, se, na veiculação, não forem preservados os direitos de personalidade (privacidade, nome, imagem e honra), configurar-se-á exercício abusivo do direito de informar. A divulgação dos dados deve ser feita de modo a preservar os direitos envolvidos, harmonizando-se o direito à liberdade de informação e os demais fundamentais colidentes.

Por fim, os critérios de utilidade e atualidade relacionam-se ao efetivo interesse público na divulgação da informação e relevância e utilidade do acesso ao dado, traduzido em benefício para a sociedade. Assim, o direito à informação deverá prevalecer se a rememoração do fato pretérito de modo contextualizado for útil e relevante à sociedade e preservar os direitos de personalidade dos envolvidos.

Diante disso, faz-se necessário aferir os mecanismos capazes de efetivar o exercício desse direito, principalmente no que tange à responsabilização dos provedores de busca na Internet, pois estes veiculam as informações pessoais sem permitir qualquer possibilidade de controle por parte dos usuários ou não dos serviços prestados.

\section{RESPONSABILIDADE CIVIL DOS PROVEDORES DE BUSCA NA INTERNET COMO INSTRUMENTO DE EFETIVAÇÃO DO DIREITO AO ESQUECIMENTO DIGITAL}


Com o fim de identificar os mecanismos capazes de favorecer a efetivação do direito ao esquecimento digital, propõe-se atribuir alguma ênfase à responsabilidade civil dos provedores de busca na Internet. Uma vez que se determinar aos provedores a desconexão entre a informação armazenada na rede e certas expressões de buscas, o direito ao esquecimento será facilitado.

\subsection{Espécies de provedores de serviços de internet}

A expressão "provedor de serviços de Internet" designa gênero bastante abrangente, cujas classificações são bem heterogêneas na doutrina. De modo genérico e conciso, conceitua-se como "a pessoa natural ou jurídica que fornece serviços relacionados ao funcionamento da Internet, ou por meio dela" (LEONARDI, 2005, p. 19). Na explicação desse autor, classifica-se em: "provedor de backbone, provedor de acesso, provedor de correio eletrônico, provedor de hospedagem e provedor de conteúdo" (LEONARDI, 2005, p. 20).

Os provedores de busca ou de pesquisa integram a categoria de provedor de conteúdo em sentido amplo, mas não se confundem com os provedores de conteúdo em sentido estrito e de informação, pois "não incluem, hospedam, organizam ou de qualquer outra forma gerenciam as páginas virtuais indicadas nos resultados disponibilizados, e limitam-se a indicar links em que podem ser encontrados os termos ou expressões de busca fornecidos pelo próprio usuário" (ANDRIGHI, on-line, 2012). O exemplo mais popularizado é o site de buscas Google.

\subsection{Direito ao esquecimento digital e responsabilidade civil dos provedores de serviços de} internet no Marco Civil da Internet

O marco civil da internet, instituído pela Lei $\mathrm{n}^{\circ}$ 12.965/2014, traz o arcabouço mínimo para regular o uso da internet. Ainda que, de forma indireta, essa lei tratou sobre o direito ao esquecimento digital, especificamente no que tange ao controle de dados pessoais. Reiterou a importância da inviolabilidade da intimidade e da vida privada (Art. $7^{\circ}, \mathrm{I}$ ), ratificando os direitos fundamentais dos quais decorre o direito ao esquecimento. E ainda estabeleceu, no inciso $\mathrm{X}$ desse artigo uma modulação do direito ao esquecimento, prevendo o direito à exclusão definitiva dos dados pessoais, a pedido do usuário titular, ao término das relações entre as partes, quais sejam usuário e provedor de aplicações (conteúdo e hospedagem). 
Critica-se, porém, a aplicação restritiva do direito ao esquecimento, quando há possibilidade de inúmeras outras violações (DONEDA, 2014). Outra crítica que se apõe, refere-se ao disposto no art. 18 da lei sob análise que isenta os provedores de acesso de responsabilidade sobre os conteúdos disponibilizados por terceiros usuários do serviço de conexão. Assim, não poderá o referido provedor ser responsabilizado por conteúdos disponibilizados por terceiros, porque o papel do provedor de acesso é atuar apenas como suporte para a conexão do usuário com a Internet, não participando da produção de conteúdo na rede.

Quanto à responsabilização civil dos provedores de serviços de hospedagem e conteúdo, nomeados na legislação em epígrafe como "provedores de aplicações de Internet”, foram regulamentadas taxativamente as hipóteses de responsabilização por danos decorrentes de conteúdo gerado por terceiros.

Quanto ao momento a partir do qual o provedor de aplicações de internet poderia tornar-se civilmente responsável por danos decorrentes de conteúdo criado e divulgado por terceiros usuários, a Lei no 12.965/2014 estabeleceu que, em regra geral, essa somente será apurada após o descumprimento de ordem judicial determinando remoção de conteúdo lesivo, se o provedor não adotar as providências técnicas cabíveis a fim de indisponibilizar o conteúdo infringente. A lei adota, portanto, a teoria conhecida como judicial notice take and down. Nesse aspecto, o Marco Civil da Internet se distanciou da técnica difundida no direito alienígena, e até então adotada pelo Superior Tribunal de Justiça, mais conhecida no direito norte-americano pela expressão em inglês notice and takedown (tradução livre: "aviso e retirada"), prevista no Communications Decency Act - CDA e no Digital Millenium Copyright Act-DMCA, assim como na Diretiva 31/2000 da Comunidade Europeia.

O art. 19 da Lei no 12.965/2014 representou a superação do modelo importado do direito comparado. Estabelece que o provedor de aplicação somente será responsável por conteúdo lesivo se não torna-lo indisponível após o conhecimento da ordem judicial que informar clara e específicamente, o conteúdo infringente.

A responsabilização civil dos provedores de serviços de internet pela preservação do conteúdo considerado infringente, após simples notificação extrajudicial realizada por 
usuário o qual se sentiu lesado, revela aspectos negativos. Leonardi (2014) alerta que reclamações frívolas ou infundadas poderiam ser atendidas, em face do receio de responsabilização, que poderia ensejar na remoção arbitrária de conteúdo lícito. De igual modo, a remoção do conteúdo por mera notificação extrajudicial, legitimaria, em algumas situações, censura temporária de informações e configura atentado à liberdade de expressão. A adoção de sistema que permitisse pronta remoção de informações on-line, mediante simples reclamação do interessado, sem análise judicial, repassaria aos provedores o poder de decidir sobre legalidade ou ilegalidade do conteúdo veiculado na rede, ferindo, assim, a reserva de jurisdição.

Ao passo que o marco regulatório, ao tratar da responsabilização civil do provedor em razão de descumprimento de ordem judicial, não condiciona a retirada de conteúdo ofensivo à necessidade de autorização judicial, mas somente estabelece hipótese de responsabilização decorrente de conteúdo gerado por terceiros. Assim, os provedores continuam livres para estabelecer as próprias políticas de privacidade e remoção de conteúdos considerados violadores das regras de utilização da rede.

\subsection{Direito ao esquecimento na sociedade da informação digital: responsabilidade dos} provedores de busca de internet e a jurisprudência brasileira

Faz-se imprescindível abordar as nuances do direito ao esquecimento no âmbito digital e as posições divergentes da jurisprudência brasileira acerca do tema da responsabilização dos provedores de busca pela chamada "indexação", que corresponde aos padrões de buscas criados pelo provedor relacionados ao nome de cada pessoa.

Tais provedores prestam serviços de busca de informações, por meio da utilização de algoritmo, selecionando as páginas eletrônicas mais relevantes para o tema pesquisado. As buscas obtidas pelo sistema desses provedores são ilimitadas, sendo impossível delimitar quais os sites referenciados são seguros ou não veiculam conteúdo ilícito, já que apresenta-se impossível a realização de filtragem prévia sobre todo conteúdo veiculado na rede e disponibilizado pelo provedor de busca por meio de links. 
Uma das decisões ${ }^{1}$ mais polêmicas envolvendo essa temática refere-se à ação promovida pela apresentadora Xuxa Meneguel em face da Google Inc., com o desiderato de compelir este provedor de busca a remover os resultados relativos à expressão "xuxa pedófila" ou, ainda, qualquer outro padrão de busca que relacionasse o nome da apresentadora a uma prática criminosa qualquer.

A Terceira Turma do Superior Tribunal de Justiça, no REsp 1.316.92, entendeu que os provedores de busca não podem ser compelidos a controlar resultados, pois são apenas meios de acesso ao conteúdo e não os responsáveis pela publicação. Desse modo, além de não poderem ser responsabilizados pelo conteúdo ilícito disponibilizado na rede, não devem censurar a abrangência da busca. Apresenta-se o aresto debatido:

CIVIL E CONSUMIDOR. INTERNET. RELAÇÃO DE CONSUMO. INCIDÊNCIA DO CDC. GRATUIDADE DO SERVIÇO. INDIFERENÇA. PROVEDOR DE PESQUISA. FILTRAGEM PRÉVIA DAS BUSCAS. DESNECESSIDADE. RESTRIÇÃO DOS RESULTADOS.NÃO-CABIMENTO. CONTEÚDO PÚBLICO. DIREITO À INFORMAÇÃO. [...] Os provedores de pesquisa realizam suas buscas dentro de um universo virtual, cujo acesso é público e irrestrito, ou seja, seu papel se restringe à identificação de páginas na web onde determinado dado ou informação, ainda que ilícito, estão sendo livremente veiculados. Dessa forma, ainda que seus mecanismos de busca facilitem o acesso e a consequente divulgação de páginas cujo conteúdo seja potencialmente ilegal, fato é que essas páginas são públicas e compõem a rede mundial de computadores e, por isso, aparecem no resultado dos sites de pesquisa.

6. Os provedores de pesquisa não podem ser obrigados a eliminar do seu sistema os resultados derivados da busca de determinado termo ou expressão, tampouco os resultados que apontem para uma foto ou texto específico, independentemente da indicação do URL da página onde este estiver inserido. 7. Não se pode, sob o pretexto de dificultar a propagação de conteúdo ilícito ou ofensivo na web, reprimir o direito da coletividade à informação. Sopesados os direitos envolvidos e o risco potencial de violação de cada um deles, o fiel da balança deve pender para a garantia da liberdade de informação assegurada pelo art. $220, \S 1^{\circ}$, da $\mathrm{CF} / 88$, sobretudo considerando que a Internet representa, hoje, importante veículo de comunicação social de massa [...]. 9. Recurso especial provido. (STJ - REsp: 1316921 RJ 2011/0307909-6, Relator: Ministra NANCY ANDRIGHI, Data de Julgamento: 26/06/2012, T3 - TERCEIRA TURMA, Data de Publicação: DJe 29/06/2012).

No mesmo sentido, destacaram-se as duas ações promovidas pelo então précandidato à Presidente Aécio Neves, em 2013, na Justiça de São Paulo, pleiteando a remoção de links e perfis em provedores de buscas da Internet (Google, Yahoo e Bing, da

1 REsp 1.316.921-RJ, Rel. Min. Nancy Andrighi, j. em 26.06.2013. Disponível em: <http://www.stj.jus.br/webstj/processo/justica/detalhe.asp?numreg=201103079096>. Acesso em: 20 jun. 2015. 
Microsoft), que relacionam seu nome ao "uso de entorpecentes", "agressões físicas à mulher" e desvio de dinheiro durante sua gestão como governador de Minas Gerais².

No processo de $\mathrm{n}^{\mathrm{o}}$ 1102747-51.2013.8.26.0100, remetido à $2^{\mathrm{a}}$ Vara Cível do Estado de São Paulo, no dia 16 de dezembro de 2013, o provedor de buscas Google afirmou que o autor "parecia sensível demais às críticas sobre sua atuação", assim como seria impossível remover o conteúdo sem prejudicar outras buscas relacionadas ao nome de Aécio Neves e, ainda se fosse possível fazê-lo, teria de empregar um controle prévio das buscas, o que considera um atentado à liberdade de expressão. O juiz de primeiro grau indeferiu a tutela antecipada pleiteada pelo autor, assim como a Desembargadora relatora do Agravo de Instrumento interposto negou o pedido de antecipação da tutela recursal. No mérito, a ação foi julgada totalmente improcedente, em março de 2015. O juiz Rodrigo Garcia Martinez salientou as falsidades das notícias, mas rejeitou as alegações autorais que consideravam os sites de busca como "bibliotecários virtuais". O magistrado ponderou que a inibição do acesso às informações configuraria em um retrocesso à livre manifestação.

Sob outro prisma, o magistrado da $43^{\mathrm{a}}$ Vara Cível da Comarca de São Paulo determinou que o Google Inc. removesse o padrão de busca que relacionava o nome de uma empresária a palavras como "profissional do sexo" e "prostituta". Na decisão, a expressão "direito a não indexação" foi utilizada como sinônimo de direito ao Esquecimento no meio virtual. O magistrado entendeu que o provedor de busca deveria retirar a associação do nome da autora à condição de "prostituta", pois estava violando inúmeros direitos da personalidade, bem como dispositivo expresso da Lei 12.965/2014, o qual consagrou o respeito aos Direitos Humanos, o desenvolvimento da personalidade e o exercício da cidadania nos meios digitais.

Em recente decisão proferida pelo Superior Tribunal de Justiça, no julgamento da Reclamação $\mathrm{n}^{\circ}$ 5.072/AC, a referida Corte manteve o posicionamento perfilhado, no sentido pelo qual o provedor de busca não pode ser responsabilizado pela remoção de determinado termo ou expressão nos seus padrões de pesquisa. O STJ entendeu que, no sopesamento entre o direito à privacidade do usuário lesado e o direito à informação,

$2 \quad 2^{\text {a }}$ Vara Cível da Comarca de São Paulo. Processo n ${ }^{\circ}$ 1102747-51.2013.8.26.0100. Disponível em: $<$ http://www.jusbrasil.com.br/diarios/documentos/121363545/processo-n-1102747-5120138260100-dacomarca-de-sao-paulo>. Acesso em: 20 jul. 2015. 
previsto no art. $220, \S 1^{\circ}$ da $\mathrm{CRFB} / 88$, deveria este último direito fundamental prevalecer. Apresenta-se o aresto discutido:

CIVIL, PROCESSO CIVIL E CONSUMIDOR. RECLAMAÇÃO. RESOLUÇÃO 12/09 DO STJ. DECISÃO TERATOLÓGICA. CABIMENTO. INTERNET. PROVEDOR DE PESQUISA VIRTUAL. FILTRAGEM PRÉVIA DAS BUSCAS. DESNECESSIDADE. RESTRIÇÃO DOS RESULTADOS. NÃO-CABIMENTO. CONTEÚDO PÚBLICO. DIREITO À INFORMAÇÃO. DADOS OFENSIVOS ARMAZENADOS EM CACHE. EXCEÇÃO. EXCLUSÃO. DEVER, DESDE QUE FORNECIDO O URL DA PÁGINA ORIGINAL E COMPROVADA A REMOÇÃO DESTA DA INTERNET. COMANDO JUDICIAL ESPECÍFICO. NECESSIDADE.

ASTREINTES. OBRIGAÇÃO IMPOSSÍVEL. DESCABIMENTO. DISPOSITIVOS LEGAIS ANALISADOS: ARTS. $220, \S 1^{\circ}$, da CF/88, 461, § $5^{\circ}$, do CPC.

$[\ldots]$

2. A filtragem do conteúdo das pesquisas feitas por cada usuário não constitui atividade intrínseca ao serviço prestado pelos provedores de pesquisa virtual, de modo que não se pode reputar defeituoso o site que não exerce esse controle sobre os resultados das buscas.

3. Os provedores de pesquisa virtual realizam suas buscas dentro de um universo virtual, cujo acesso é público e irrestrito, ou seja, seu papel se restringe à identificação de páginas na web onde determinado dado ou informação, ainda que ilícito, estão sendo livremente veiculados. Dessa forma, ainda que seus mecanismos de busca facilitem o acesso e a consequente divulgação de páginas cujo conteúdo seja potencialmente ilegal, fato é que essas páginas são públicas e compõem a rede mundial de computadores e, por isso, aparecem no resultado dos sites de pesquisa.

4. Os provedores de pesquisa virtual não podem ser obrigados a eliminar do seu sistema os resultados derivados da busca de determinado termo ou expressão, tampouco os resultados que apontem para uma foto ou texto específico, independentemente da indicação do URL da página onde este estiver inserido.

5. Não se pode, sob o pretexto de dificultar a propagação de conteúdo ilícito ou ofensivo na web, reprimir o direito da coletividade à informação. Sopesados os direitos envolvidos e o risco potencial de violação de cada um deles, o fiel da balança deve pender para a garantia da liberdade de informação assegurada pelo art. $220, \S 1^{\circ}$, da CF/88, sobretudo considerando que a Internet representa, hoje, importante veículo de comunicação social de massa.

$[\ldots]$

(Rcl 5.072/AC, Rel. Ministro MARCO BUZZI, Rel. p/ Acórdão Ministra NANCY ANDRIGHI, SEGUNDA SEÇÃO, julgado em 11/12/2013, DJe 04/06/2014). (grifou-se).

Contrapondo-se à decisão em análise, entende que, embora o provedor de busca não seja compelido a fiscalizar previamente o conteúdo dos resultados apresentados aos usuários, com base nas palavras-chaves adotadas, é possível atribuir àquele o "dever de retirada de determinada informação que leve à violação de direito subjetivo de outrem, desde que haja conhecimento efetivo pelo provedor desta lesão à esfera subjetiva do indivíduo" (BINICHESK, 2011, p. 256). 
O entendimento reiterado defendido pelo Superior Tribunal de Justiça merece ser repensado, pois "a atividade exercida pelo motor de busca tem poder decisivo na difusão nacional e internacional do fato disponibilizado na Internet". Assim, a possibilidade de cada provedor de conteúdo se utilizar de ferramentas para desindexação de informações não isenta a responsabilização do provedor de pesquisa que continua difundindo os dados indesejadamente (MARTINEZ, 2014, p. 148).

É indiscutível a existência de relação de consumo no serviço prestado pelos sites de busca, via Internet, pois os provedores de pesquisa auferem lucro tanto indireta quanto diretamente. Quanto ao lucro direto, apresenta-se a relação contratual entre o provedor de busca e outros provedores de conteúdo ou hospedagem, dentre os quais estes pagam para aquele colocá-los na ordem de preferência das buscas.

Dessa forma, ao listarem os padrões de busca com base em preferências, tais provedores de busca contribuem diretamente para o resultado obtido. Assim, se o padrão de busca for por si só capaz de violar inúmeros direitos de personalidade, deveria tal provedor ser responsável por indisponibilizá-lo.

Outrossim, seria possível responsabilizar o provedor de busca ou pesquisa pelos conteúdos ofensivos presentes nas indicações de busca, assim como condená-los a remover o padrão de busca os quais levem a resultados hábeis a degradar a personalidade do usuário, pois, embora não tendo a capacidade de filtrar todo conteúdo da rede, tais provedores são capazes tecnicamente de indisponibilizar os resultados com conteúdo ofensivo, já que seriam estes capazes de listar ordens de preferência.

Tais informações permitem ao provedor em questão personalizar os padrões de busca conforme as preferências pessoais e de mercado, de modo que este assume a responsabilidade pelo resultado das buscas, ao manipulá-los. Diante disso, coerente se faz a responsabilização desse provedores, com o fito de garantir o exercício do direito ao esquecimento digital. 


\section{REGULAMENTAÇÃO LEGISLATIVA DO DIREITO AO ESQUECIMENTO DIGITAL:}

Em meio a afirmação do direito ao esquecimento na doutrina e na jurisprudência brasileira, indaga-se acerca da necessidade de normatização do direito em análise. Apresentar-se-á o conteúdo dos Projetos de Lei nº 7881/2014 e no 1676/2015, investigando a sua abrangência e os pontos nefráugicos das propostas legislativas. Incidentalmente, por fim, analisar-se-ão as experiências estrangeiras (Espanha, Itália e Rússia) acerca do direito ao Esquecimento na Sociedade da Informação Digital.

\subsection{Dilema entre a necessidade de regulamentação e a aplicação da decisão judicial com} base principiológica

O "Direito não nasce do nada", advém do mundo do ser, dos fatos sociais, os quais se impõe, mesmo contra a imutabilidade desejada pelos Códigos, sua força motriz. Assim, percebe-se que o Direito anseia por maiores aberturas sociais, a fim de solucionar as mais diversas formas de conflito (PERLINGIERI, 2008).

Desse modo, infere-se que a legislação é incapaz de exercer um papel totalizante diante da diversidade de novas relações jurídicas em ascensão. Por isso, a força unificadora da Constituição se impõe de modo a acolher a volatilidade do mundo do ser. Os princípios constitucionais, os quais se irradiam diretamente sobre as relações entre particulares, são importantes instrumentos para o intérprete do Direito Civil.

Está superada a ideia pela qual a solução das controvérsias deveria ser encontrada no texto legal, ante à existência de um arcabouço vasto de princípios fundamentais, capazes de fornecer os alicerce da ordem jurídica. Afinal, o papel unificador do sistema é desempenhado de maneira mais incisiva pelo texto constitucional (PERLINGIERI, 2007).Diante disso, percebe-se que o direito ao esquecimento digital não reclama normatização como condição necessária a ser tutelado na ordem jurídica nacional. Afinal, como explicitado, ele decorre diretamente da cláusula de proteção e promoção da pessoa humana, assim como caminha conexo ao direito à Privacidade.

Ainda que haja inexistente legislação, regulamentando diretamente o direito ao esquecimento digital, o magistrado, diante do caso concreto, possui inúmeras ferramentas para fundamentar a sua decisão, diante do sopesamento entre princípios constitucionais, a fim 
de garantir o exercício da autodeterminação informativa. Contudo, especialmente quanto à polêmica envolvendo a responsabilização dos provedores de busca pela remoção de padrões de pesquisa lesivos aos direitos de personalidade, encontra-se o intérprete diante da tênue fronteira entre uma decisão jurídica e política. Por apresentar conteúdo político, diz-se que cabe ao Poder Legislativo definir a questão.

Assim, afirma-se se "altamente recomendável no Brasil a edição de uma lei geral e sistêmica para disciplinar a proteção de dados pessoais, como ocorre em praticamente todos os Estados europeus, e em países como Canadá, Argentina, Uruguai, Chile e México" (SARMENTO, 2015, p. 47).

Desta feita, a inexistência de legislação específica regulamentando as nuances do direito ao esquecimento impede que se admita a sua existência, muito embora sua aplicação concreta já exista. $\mathrm{O}$ maior impacto com a normatização seria por um fim na resistência e negação desse direito por parte da doutrina e, especialmente, da jurisprudência brasileira, encerrando as incertezas que pairam sobre a aplicação do instituto (MARTINEZ, 2014, p. 190).

\subsection{Análise dos projetos de Lei $n^{\circ} 7881 / 2014$ e n $n^{\circ}$ 1676/2015}

O projeto de Lei $\mathrm{n}^{\circ}$ 7881/2014, apresentado pelo então Presidente da Câmara dos Deputados Eduardo Cunha, sintetiza o debate extremamente complexo acerca do direito ao esquecimento digital e da responsabilização civil dos provedores de busca na Internet, em apenas um único artigo com conteúdo material. Observa-se:

Art. $1^{\circ}$ É obrigatória a remoção de links dos mecanismos de busca da internet que façam referência a dados irrelevantes ou defasados, por iniciativa de qualquer cidadão ou a pedido da pessoa envolvida. (grifou-se).

A justificativa apresentada em conjunto ao referido projeto baseou-se na reprodução integral do texto de uma reportagem veiculado pelo jornal "O Globo", em 4 de agosto de 2014. Faz-se referência a suposta aprovação de uma legislação regulamentadora do direito ao esquecimento pelo Tribunal de Justiça da União Europeia, estabelecendo a obrigatoriedade de remoção pelos provedores de busca na Internet das informações consideradas irrelevantes ou defasadas.

O projeto tem sido alvo de críticas em virtude da simplificação de um assunto com tantas vicissitudes, especialmente quanto a enumeração de critérios tão vagos como a 
irrelevância e o defasamento das informações. O conceito de irrelevância contrapõe-se à noção de relevância histórica e interesse público. Estas duas circunstâncias, se presentes, são fortes balizas a indicar que o direito à informação deve prevalecer sobre o direito ao Esquecimento.

Pertinente ao critério das informações defasadas, tal conceito seriam compreendido por dados referentes ao passado os quais tenham se tornado sem utilidade para a coletividade, principalmente em razão do tempo (MARTINEZ, 2014, p. 189). Diante disso, surgem novas indagações: haveria um prazo de vida útil para as informações? A quem deveria ser atribuído tal juízo de valor?

A identificação das informações tidas como inúteis para a coletividade e defasadas pelo critério temporal continuará sendo papel do intérprete do direito, que, no caso concreto, realizará a valoração necessária, de modo a concretizar o comando legal tendente a responsabilizar o provedor de busca pela retirada de tais dados defasados. Afinal, não poderia a lei estabelecer prazos fixos para a vida últil das informações, pois aí se estaria neutralizando as circusntâncias externas que qualificam o caso concreto.

Por sua vez, o projeto de Lei $\mathrm{n}^{\mathrm{o}}$ 1676, apresentado pelo Deputado Veneziano Vital do Rêgo, no ano de 2015, é bem mais abrangente do que o anterior, pois, além de criminalizar a veiculação de fotos ou vídeos de terceiros sem autorização ou finalidade lícita, institucionaliza o direito ao esquecimento para além do universo digital. Apresenta-se os artigos pertinentes ao objeto da pesquisa:

Art. $3^{\circ} \mathrm{O}$ direito ao esquecimento é expressão da dignidade da pessoa humana, representando a garantia de desvinculação do nome, da imagem e demais aspectos da personalidade relativamente a fatos que, ainda que verídicos, não possuem, ou não possuem mais, interesse público.

Parágrafo único. Os titulares do direito ao esquecimento podem exigir dos meios de comunicação social, dos provedores de conteúdo e dos sítios de busca da rede mundial de computadores, internet, independentemente de ordem judicial, que deixem de veicular ou excluam material ou referências que os vinculem a fatos ilícitos ou comprometedores de sua honra.

Art. $4^{\circ}$ Os meios de comunicação social, os provedores de conteúdo e os sítios de busca da rede mundial de computadores, internet, devem criar, dentro de noventa dias, departamentos específicos para tratar do direito ao esquecimento, com a disponibilização de endereços físicos e telefones, destinados a receber reclamações, que deverão ser registradas numericamente.

$\S 1^{\circ}$ Os meios de comunicação social, os provedores de conteúdo e os sítios de busca da rede mundial de computadores, internet, na hipótese de não reconhecerem a existência do direito ao esquecimento, deverão fornecer ao requerente, por escrito, motivadamente, as razões da negativa, em até trinta dias.

$\S 2^{\circ} \mathrm{O}$ prazo máximo de trinta dias mencionado no $\S 1^{\circ}$ não constitui impedimento para a pronta solução de casos mais urgentes. 
$\S 3^{\circ} \mathrm{O}$ descumprimento do dever de instalação dos departamentos encarregados do respeito ao direito ao esquecimento ou o seu mau funcionamento acarretará a responsabilidade dos meios de comunicação social, dos provedores de conteúdo e dos sítios de busca da rede mundial de computadores, internet, a ser promovida por meio de ação civil pública. (grifou-se).

O referido projeto unifica o critério da informação suscetível de ser excluída em torno da inexistência de interesse público na sua veiculação, ainda que essa seja verídica. Assim, fica resguardada a possibilidade de desvinculação do nome, da imagem e de qualquer outro aspecto da personalidade, podendo ser exigida tal providência a qualquer veículo de comunicação social, inclusive os provedores de busca.

O parágrafo único do art. $3^{\circ}$ deixa claro que os "sítios de busca da rede mundial de computadores" deverão deixar de veicular ou excluir material ou referência que vinculem o lesado a fato ilícito ou comprometa sua honra, independentemente de ordem judicial. Diante disso, o Projeto supracitado, caso aprovado, revogaria parcialmente a previsão do art. 19 da Lei $\mathrm{n}^{\circ} 12.965 / 2014$, ao prever a responsabilização dos provedores diante do descumprimento de notificação extrajudicial.

Um dos pontos mais interessantes do Projeto de Lei $n^{\circ}$ 1676/2015 refere-se a imposição às empresas exploradoras de atividades comunicativas de criarem, no prazo de 90 dias, "departamentos específicos para tratar do direito ao esquecimento, com a disponibilização de endereços físicos e telefones, destinados a receber reclamações, que deverão ser registradas numericamente".

Tal aspecto certamente será alvo de muitas discussões nas Comissões Especiais do Congresso Nacional, afinal, estabelece uma imposição de grande impacto econômico às empresas. Entretanto, tal previsão tornaria muito mais efetiva e ágil a concretização do direito ao esquecimento, pois, muitas vezes, a demora no provimento jurisdicional, prolonga de forma geométrica a extensão dos danos no ambiente virtual.

Em termos de legislação, jurisprudência e doutrina, a experiência estrangeira ganha destaque quanto à definição dos limites do direito ao Esquecimento, especialmente no que tange à proteção dos dados pessoais no âmbito virtual. As diretivas do Tribunal de Justiça da União Europeia expressam a importância que o tema em análise possui na perspectiva comparada. 
O Comunicado da Comissão Europeia, intitulado "A comprehensive approach on personal data protection in the European Union", e a proposta de atualização da Diretiva 95/46/CE, dirigidos ao Parlamento Europeu, Comitê Econômico e Social e Comitê das Regiões, regulamentaram a proteção de dados pessoais na União Europeia, de modo a facilitar os direitos de acesso, retificação, oposição e cancelamento dos dados pessoais no meio digital.

O consentimento do usuário de Internet, o respeito à legítima finalidade, assim como a definição do período de armazenamento das informações e obrigatoriedade de sua remoção, após expirado o prazo, são algumas diretrizes de gestão na rede estabelecidas pela Comissão Europeia.

O Tribunal de Justiça da União Europeia julgou, em 2012, ação promovida pela Agencia Española de Protección de Datos, em litisconsórcio com um particular contra a Google Inc. Espanha. Buscava-se compelir o provedor de busca a indisponibilizar os padrões de pesquisa os quais relacionassem o usuário à existência de processo de execução extinto há dez anos. A Curia Europeia responsabilizou o provedor Google, obrigando-o a retirar o conteúdo ofensivo, a fim de resguardar o direito ao esquecimento no âmbito virtual.

No plano interno, a Espanha editou a Lei Orgânica n 15/1999, conhecida como Lei de Proteção de Dados de Caráter Pessoal (LOPD), a qual regulamentou o direito à "autodeterminação informativa", exige o prévio consentimento do indivíduo para a veiculação de seus dados sensíveis, assim como resguarda a revogação da autorização. A legislação em comento prevê, ainda, a responsabilização do provedor de busca, caso não providencie a remoção de dados, quando demandado (MARTINEZ, 2014, p. 114).

No ordenamento italiano, o direito ao esquecimento vem sendo discutido há anos, pois a Suprema Corte da Itália, desde 20 de novembro de 1996, considerou que a reivindicação para obter posse exclusiva das informações pessoais tem superior relevância se comparado ao direito de publicá-las, consoante interpretação do art. $2^{\circ}$ da Constituição Italiana.

Recentemente, na decisão no 5.525, de 5 de abril de 2012, a Suprema Corte de Roma confirmou o entendimento acerca do direito à autodeterminação informativa, entendendo que "não é permitido divulgar mais uma vez, após tempo substancial, notícias as quais foram 
publicadas legalmente ". Ademais, tal direito deve ser "entendido como um interesse de todas as pessoas de não permanecer indefinidamente exposto a danos contínuos a sua honra ou reputação através da publicação de uma notícia legalmente publicada no passado" (MEZZETTI, 2015, on-line). Finalmente, a experiência Russa destaca-se pela atualidade nas discussões sobre a regulamentação desse direito, pois o Parlamento Russo (Duma) aprovou, no dia 3 de julho de 2015, uma Lei, compelindo os provedores de busca na Internet, sob pena de multa, a remover os links com informações pessoais, a fim de consagrar o que ficou conhecido, na Europa, como "direito à desindexação".

A supracitada Lei ainda está pendente de sanção pelo Presidente Vladmir Putin, ao passo que o Yandex, maior provedor de buscas da Rússia, posicionou-se no sentido de que as limitações apresentadas pela lei irão refletir um desequilíbrio entre os interesses público e privado, pois impedirá o acesso das pessoas a informações importantes do ponto de vista histórico. Salienta-se que o fato ainda é recente para para se realizar conjecturas acerca das consequências da referida lei no território russo e até mesmo em nível internacional.

\section{CONCLUSÃO}

Evidenciou-se que a sociedade da informação digital trouxe grandes avanços para a democratização do direito à informação; porém, ao mesmo tempo, o ambiente virtual tornou-se um meio propício ao desenvolvimento de violações aos direitos de personalidade. A arquitetura das redes virtuais explica a vulnerabilidade do direito à privacidade nesse meio, especialmente no que tange ao descontrole do fluxo das informações pessoais.

Diante disso, surgiu a necessidade de exercer controle sobre o espaço informacional, o que culminou com a afirmação do direito ao esquecimento digital. Tal direito pode ser perfeitamente enquadrado na categoria dos Direitos Humanos, Fundamentais e de Personalidade, originado do núcleo de proteção do direito à privacidade e do princípio da dignidade da pessoa humana.

Aferiu-se alguns parâmetros os quais devem ser utlizados pelos magistrados, diante do caso concreto, a fim de harmonizar os princípios constitucionais colidentes, conferindo-lhes a máxima efetividade diante das possibilidades fáticas e jurídicas existentes, dentre estes está o da utilidade na veiculação da informação, interesse público e 
atualidade dos dados. Ausentes tais critérios, não se justifica que se obste ao exercício do direito ao esquecimento.

Constatou-se que o marco civil da internet trouxe alguns dispositivos que regulamentaram indiretamente o exercício do direito ao esquecimento, especialmente no que tange à proteção de dados pessoais, embora tenha restado omisso quanto à responsabilização dos provedores de busca na internet, demonstrando incompletude quanto à efetivação do direito ao esquecimento digital.

Embora a jurisprudência nacional, destacando-se recentes decisões do Superior Tribunal de Justiça, tenha isentado o provedor de busca da obrigação de remover padrões de pesquisa capazes de lesar inúmeros direitos de personalidade, concluiu-se que estes provedores deveriam ser responsabilizados pela remoção dos conteúdos ofensivos, pois são diretamente responsáveis pelos resultados pesquisados, ao passo que enumeram listas de resultados preferenciais.

Finalmente, percebeu-se que, embora o direito ao esquecimento não reclame previsão normativa para ser exercido, haja vista derivar diretamente do princípio da dignidade da pessoa humana, faz-se imprescindível uma legislação regulamentadora, com o desiderato de por fim à resistência da jurisprudência nacional, especialmente no que tange à responsabilização dos provedores de busca, acompanhando as transformações identificadas no plano internacional.

\section{REFERÊNCIAS}

ANDRIGHI, Fátima Nancy. A responsabilidade civil dos provedores de pesquisa via internet. VOL. 78, nº 3, São Paulo: Rev. TST, 2012.

ALEXY, Robert. Teoria dos direitos fundamentais. Tradução Virgílio Afonso da Silva. São Paulo: Malheiros, 2008.

BAUMAN, Zygmunt. Privacidade, sigilo, intimidade, vínculos humanos- e outras baixas colaterais da modernidade líquida. In Danos colaterais: desigualdades sociais numa era global. Tradução de Carlos Alberto Medeiros. Rio de Janeiro: Zahar, 2013.

BUCAR, Daniel. Controle temporal de dados: o direito ao esquecimento. Civilistica.com, Rio de Janeiro, ano 2, n. 3, jul.-set. 2013. Disponível em: <http://civilistica.com/controletemporal-dedados-o-direito-ao-esquecimento/>. Acesso em: 29 abr. 2015. 
BINICHESKI, Paulo Roberto. Responsabilidade civil dos provedores de internet: direito comparado e perspectivas de regulação no direito brasileiro. São Paulo: Juruá, 2011.

BRASIL. Código Civil. Lei n.10.406, de 10 de janeiro de 2002. Disponível em: <http://www.planalto.gov.br/ccivil_03/leis/2002/110406.htm>. Acesso em: 14 abr. 2015.

BRASIL. Constituição (1988). Constituição da República Federativa do Brasil. São Paulo: Saraiva, 2015.

. Lei $\mathrm{n}^{\circ} 12.965$, de 23 de abril de 2014. Estabelece princípios, garantias, direitos e deveres para o uso da Internet no Brasil. Brasília, 23 de abril de 2014.

Disponível em: <http://www.planalto.gov.br/ccivil_03/_ato20112014/2014/lei/112965.htm>. Acesso em: 11 jun. 2015.

.Superior Tribunal de Justiça, $4^{\text {a }}$ Turma. REsp. 1.334.097-RJ, Rel. Min. Luis Felipe Salomão, j. em 28.05.2013. Disponível em: <https://ww2.stj.jus.br/revistaeletronica/Abre_Documento.asp?sLink=ATC\&sSeq=310065 $10 \& s R e g=201201449107 \& s D a t a=20130910 \& s T i p o=5 \&$ formato=PDF $>$. Acesso em: 20 jun. 2015.

. REsp 1.316.921-RJ, Rel. Min. Nancy Andrighi, j. em 26.06.2013. Disponível em: <http://www.stj.jus.br/webstj/processo/justica/detalhe.asp?numreg=201103079096〉. Acesso em: 20 jun. 2015.

Rcl 5.072, Rel. Min, Nancy Andrighi, j. em 11.12.2013. Disponível em: <http://stj.jusbrasil.com.br/jurisprudencia/25138018/reclamacao-rcl-5072-ac-20100218306-6-stj/inteiro-teor-25138019>. Acesso em: 20 jul. 2015.

CANOTILHO, José Joaquim Gomes. Direito constitucional e teoria da constituição. 4. ed. Lisboa:Almedina, 2000.

CASTELlanO, Pere Simón. The Right to be Forgotten under European Law: Constitutional Debate. Lex Electronica, vol 16.1, Winter 2012.

CASTELLS, Manuel. A sociedade em rede. Tradução de Roneide Venâncio Majer. 8. ed. rev. ampl. São Paulo: Paz e Terra, 2005.

DENNINGER, Erhard. Racionalidad tecnológica, responsabilidad ética y derecho postmoderno. Doxa, n. 14, 1993.

DONEDA, Danilo. A proteção da privacidade e de dados pessoais no Brasil. Observatório Itaú Cultural, v. 16, p.136-150, jan.jun.2014. 
EUROPEAN COMMISSION. Communication from the Comission to the European Parliament, the Council, the Economic and Social Committee and the Committee of the Regions - A comprehensive approach on personal data protection in the European Union. Brussels: november 2010. Disponível em: <http://bit.ly/bXUXvi>. Acesso em: 20 jun. 2015.

FACHIN, Luiz Edson. Estatuto jurídico do patrimônio mínimo. 2. ed. Rio de Janeiro: Renovar, 2006.

FLEISCHER, Peter. Foggy thinking about the right to oblivion. Peter Fleischer: Privacy...? [blog], mar. 2011. Disponível em: <http://peterfleischer.blogspot.com.br/2011/03/foggy--thinking-about-right-tooblivion.html> Acesso em: 29 abr. 2015.

GALVÃO, Helder. Direito de imagem e fotojornalismo. In: SCHREIBER, Anderson (coord.). Direito e mídia. São Paulo: Atlas, 2013.

JEFFRIES, Stuart. Why we must remember to delete - and forget - in the digital age. The Guardian, 30 jun. 2011. Disponível em:

<http://www.theguardian.com/technology/2011/jun/30/remember-delete-forget-digitalage>Acesso em: 29 jul. 2015.

LEONARDI, Marcel. Responsabilidade Civil dos Provedores de Serviços de Internet. São Paulo: Editora Juarez de Oliveira, 2005.

. Responsabilidade civil dos provedores de serviços de Internet. Coordenadas fundamentais. Jus Navigandi, Teresina, ano 15, n. 2592, 6 ago. 2010. Disponível em: <http://jus.com.br/artigos/17128>. Acesso em: 16 jul. 2015.

LIMA, Erik Noleta Kirk Palma Lima. Direito ao Esquecimento: discussão europeia e sua repercussão no Brasil. Revista de Informação Legislativa, Brasília, v. 50, n. 199, p. 271 283, jul./set. 2013.

MARTINEZ, Pablo Dominguez. Direito ao Esquecimento: a proteção da memória individual na sociedade da informação. Rio de Janeiro: Lumen Jures, 2014.

MAYER-SCHÖNBERGER, Viktor. Delete: the virtue of forgetting in the digital age. New Jersey: Princeton University, 2009.

MORAES, Maria Celina Bodin de. Na medida da pessoa humana: estudos de direito civil. Rio de Janeiro: Renovar, 2010.

ORWELL, George. 1984. Tradução de Wilson Velloso. Companhia Editorial Nacional: São Paulo. Disponível em: <http://about-brazil.org/books/1984.pdf> Acesso em: 29 jul. 2015. 
PERLINGIERI, Pietro. O direito civil na legalidade constitucional. Rio de Janeiro: Renovar, 2008.

. Perfis do direito civil: uma introdução ao direito civil constitucional. Rio de

Janeiro, RJ: Renovar, 2007.

RODOTÀ, Stefano. A vida na sociedade da vigilância: a privacidade hoje. Organização, seleção e apresentação de Maria Celina Bodin de Moraes. Tradução: Danilo Doneda e Luciana Cabral Doneda. Rio de Janeiro: Renovar, 2008.

SÃO PAULO. $2^{\text {a }}$ Vara Cível. Processo no 1102747-51.2013.8.26.0100. Disponível em: <http://www.jusbrasil.com.br/diarios/documentos/121363545/processo-n-1102747-

5120138260100-da-comarca-de-sao-paulo>. Acesso em: 20 jul. 2015.

SARMENTO, Daniel. Direitos fundamentais e relações privadas. Rio de Janeiro, RJ: Lumen Juris, 2008.

. Parecer: liberdades comunicativas e direito ao esquecimento na ordem constitucional brasileira. Rio de Janeiro, 2015.

SARLET, Ingo Wolfgang. Dignidade da pessoa humana e direitos fundamentais na Constituição Federal de 1988. 7. ed. rev. atual. Porto Alegre: Livraria do Advogado Ed., 2009.

SCHEREIBER, Anderson. Direitos da personalidade. São Paulo: Atlas, 2011.

TEPEDINO, Gustavo. Temas de direito civil. 4 ed. rev. atual. Rio de Janeiro: Renovar, 2008.

WARREN, Samuel Dennis; BRANDEIS, Louis Dembitz. The right to privacy. Harvard: Law Review. 1890.

WESTIN, Alan F. Privacy and freedom. New York: Atheneum, 1967

WIENER, Norbert. Cibernética e Sociedade - o uso humano de seres humanos. 4ed. São Paulo: Cultrix, 1973 